\title{
Burden of coronary heart disease on the Iranian oil industry (1999-2000)
}

B. Larijani, ${ }^{1}$ H. Fakhrzadeh, ${ }^{1}$ M. Mohaghegh, ${ }^{2}$ R. Pourebrahim ${ }^{1}$ and M. R. Akhlaghi ${ }^{1}$

$$
\begin{aligned}
& \text { عبs مرض القلب التاجي في شركات حناعة النفط الإيرانية (1999-2000) }
\end{aligned}
$$

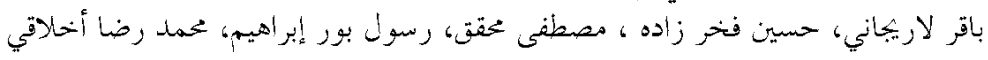

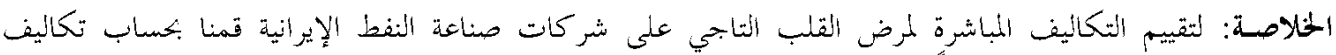

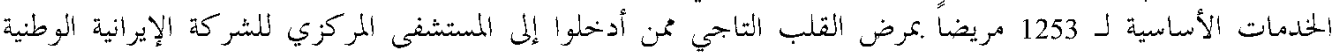

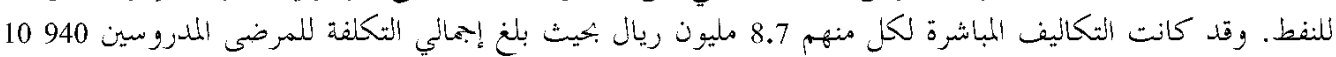

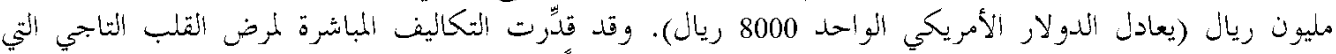

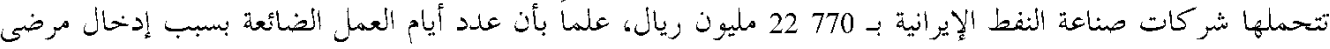

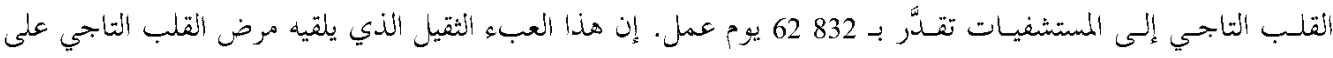

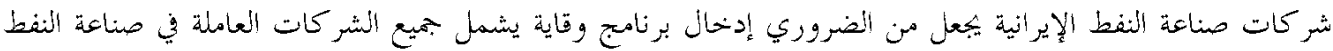
الإيرانية ويُعنى بمرض أنقلب التاجي.

ABSTRACT To estimate the direct cost of coronary heart disease (CHD) to the Iranian oil industry, we calculated the cost of essential services for $1253 \mathrm{CHD}$ patients admitted to the National Iranian Oil Corporation (NIOC) Central Hospital. The direct cost of CHD at the Hospital was 10940 million rials (US\$1 $=8000$ rials), or 8.7 million rials per patient. The direct cost of CHD to the Iranian oil industry was estimated at 22770 million rials. Working days lost to workers hospitalized for $\mathrm{CHD}$ amounted to 62832 . The heavy burden of $\mathrm{CHD}$ on the Iranian oil industry necessitates the introduction of an industry-wide prevention programme.

Charge imposée par les coronaropathies sur l'industrie pétrolière iranienne (1999-2000)

RESUME Afin d'estimer le coût direct des coronaropathies pour l'industrie pétrolière iranienne, nous avons calculé le coût des services essentiels pour 1253 patients souffrant de coronaropathie admis à l'hôpital central de la National Iranian Oil Corporation. Le coût direct des coronaropathies dans cet hôpital central s'élevait à 10940 millions de rials (USD $1=8000$ rials), soit 8,7 millions de rials par patient. On estime que le coût direct des coronaropathies pour l'industrie pétrolière iranienne s'élevait à 22770 millions de rials. II y a eu 62832 journées de travail de perdues pour les ouvriers hospitalisés pour coronaropathie. La lourde charge imposée par les coronaropathies sur l'industrie pétrolière iranienne rend nécessaire l'introduction d'un programme sectoriel de prévention des coronaropathies.

${ }^{1}$ Endocrine and Metabolism Research Centre, Doctor Shariati Hospital, Tehran University, Tehran, Islamic Republic of Iran.

${ }^{2}$ Health Research and Education Unit, Healthcare Organization, National Iranian Oil Corporation, Tehran, Islamic Republic of Iran.

Received: 30/07/02; accepted: 27/03/03 


\section{Introduction}

The restructuring of communities across Asia has been accompanied by an alarming increase in the incidence of coronary heart disease (CHD) [1]. Modern technology, increasing urbanization, rapid economic growth and lifestyle changes have made a significant contribution to the rising incidence of CHD in these communities. Mortality figures for Asian countries show a rising tide of CHD similar to that experienced by the industrialized West in the 1950s and 1960s [2].

The results of the World Health Organization Multinational Monitoring of Trends and Determinants in Cardiovascular Disease (MONICA) Project have shown that cardiovascular disease causes between $25 \%-45 \%$ of all deaths worldwide and is the leading cause of death in a majority of countries [3,4]. More than half of these deaths occur in developing countries [5].

Although not traditionally considered prevalent, CHD and cerebrovascular accidents, or strokes, have now become the leading causes of death in China [6,7]. In Southeast Asia too, the prevalence of CHD is on a steep upward curve. Cardiovascular disorders, primarily CHD, have also become a leading cause of death in India $[8,9]$. It has been estimated that the number of deaths due to CHD will have doubled there between 1985 and 2015, at which time CHD will displace infectious diseases as the leading cause of death [10].

The heavy economic burden of cardiovascular disease strains the imagination. In the United States of America, the cost of CHD in the year 2000 has been estimated at more than US\$ 118000 million [11]. In 1996-1997, the cost of patients with myocardial infarctions in the Islamic Republic of Iran was estimated at 170000 million rials (US\$ $1=8000$ Iranian rials) [12].
To estimate the economic cost of coronary artery disease to the Iranian oil industry in 1999, the Research and Education Unit of the Healthcare Organization of the National Iranian Oil Corporation (NIOC) calculated total hospitalization costs of CHD patients admitted to the NIOC Central Hospital in Tehran in that year and then estimated the total burden imposed by CHD on the Iranian oil industry.

\section{Methods}

For this cross-sectional study, we obtained a list from the records office of the NIOC Central Hospital, Tehran, of all patients admitted between 21 March 1999 and 20 March 2000 because of coronary artery disease (International Classification of Diseases, 9th revision, codes 410-414). We estimated the overall cost using a pricelist of essential goods and services based on the tariffs set by the Healthcare Department of the NIOC Healthcare Organization. The final cost of hospitalized patients was calculated according to the following linear equation [13]:

Total cost $=\Sigma$ (Unit price of each service $\times$ Number of units of service delivered)

At the same time NIOC-dependent healthcare centres throughout the country were requested to provide the study team with a statement of the cost of CHD patients in their care during the study interval.

Direct costs were defined as costs directly attributable to the production or delivery of a service, e.g. coronary angioplasty. Indirect costs were the social costs attributable to such items as loss of productivity, absenteeism and loss of manufacturing manpower.

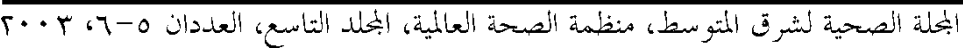


We only assessed the cost of patients hospitalized with coronary events, i.e. angina pectoris, myocardial infraction and sudden cardiac death. We excluded the cost of outpatient services delivered during the study interval. Likewise, indirect costs due to structural wear and tear, use of diagnostic equipment and water and electric utilities that were not attributable to any specific function or action were not calculated as part of this study.

\section{Results}

Total inpatient admissions for cardiovascular disease were 1670 individuals, of whom 1253 (75\%) were CHD patients. Of the patients with CHD, 877 (70\%) were men and 376 (30\%) women. Average patient age was $50.4 \pm 8.3$ years. Of all patients, $64.8 \%$ (812) were aged $40-55$ years (Figure 1).

Of the 1253 patients, 89 (7.1\%) died in hospital as a result of their disease. Of the 13297 admissions overall to the NIOC

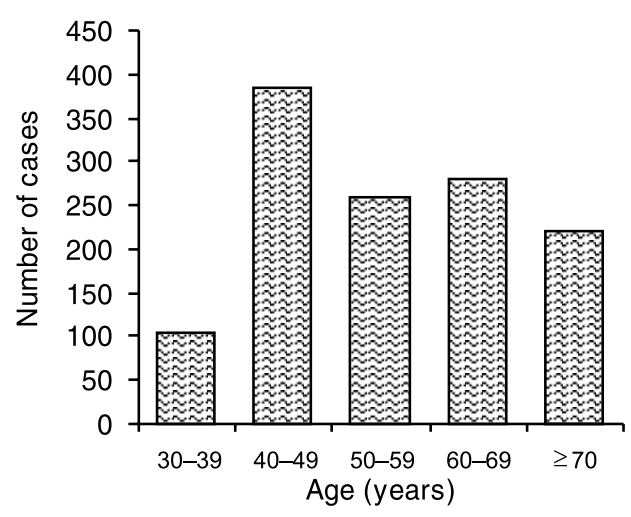

Figure 1 Age distribution of coronary heart disease patients admitted to the National Iranian Oil Company Central Hospital in 1999-2000
Central Hospital, 201 (1.5\%) died as a result of their disease. Therefore, $44.3 \%$ of all deaths and $9.4 \%$ of all admissions to the NIOC Central Hospital were due to CHD.

Figure 2 shows the overall cost of various services received by cardiovascular patients hospitalized in 1999-2000 at the NIOC Central Hospital. 'Bed-day' is the cost of having someone occupy a hospital bed for 1 day. 'Visit' is the average cost per patient per visit. The overall direct cost of patients hospitalized there was 10940 million rials, equal to an expenditure of 8.70 million rials per patient. The overall number of patients hospitalized for CHD in 19992000 by NIOC healthcare centres was 2618. By taking the product of the latter figure and the per capita cost of hospitalization given above, the estimated direct cost of CHD patients to the oil industry during the study period was 22800 million rials.

\section{Cost of absenteeism}

Patients spent 10400 days in the hospitalincluding in the coronary care unit (CCU), cardiac intensive care unit (ICU) and cardiac surgery wards-during the study period. The average length of hospital stay for CHD was therefore 8.3 days. Of the 1253 patients, 660 were NIOC operational staff who were hospitalized for coronary artery by-pass grafting (CABG) because of an acute coronary event. Each of these patients was given at least 30 consecutive days sick leave after discharge from hospital. In contrast, patients admitted for CHD but not undergoing CABG were given an average of 14 consecutive days sick leave after discharge. Thus, a total of 38502 days' absence from work [10 $400+$ $(660 \times 30)+(593 \times 14)]$ were registered by CHD patients during the study period; that is, on average, 30.7 days off work per hospitalized CHD patient in 1999-2000.

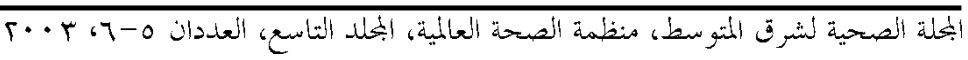




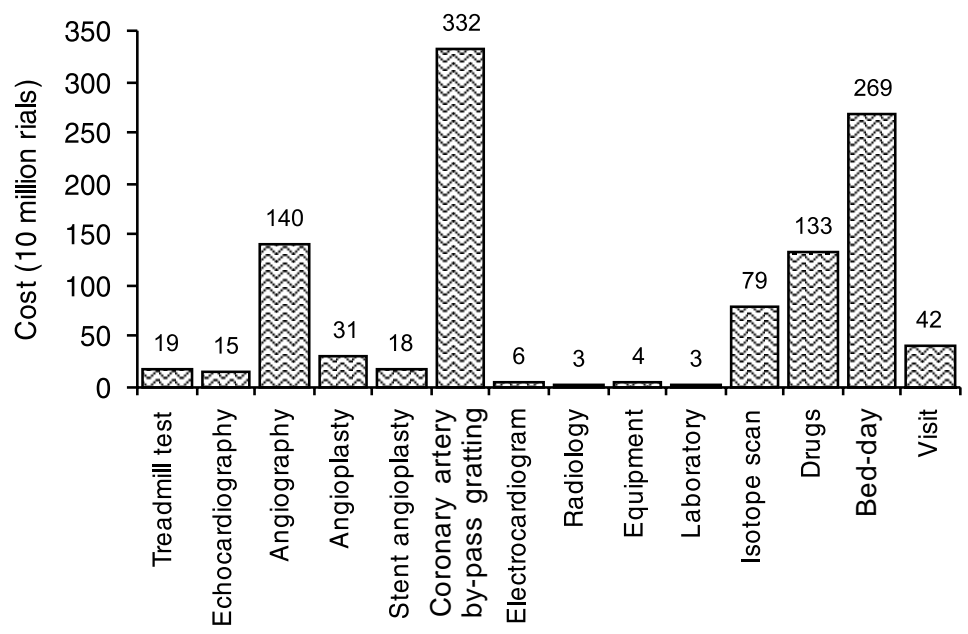

Figure 2 Comparison of costs of medical services to coronary heart disease patients admitted to the National Iranian Oil Company Central Hospital in 1999-2000 (US\$ $1=8000$ Iranian rials)

Given that 2618 people within the oil industry were hospitalized for CHD during the study interval, the total number of days absent from work because of CHD can be estimated at 80373 , i.e. nearly 220 person-years including holidays, compensated leave and weekend days. The majority of these patients were blue-collar workers in the oil industry who are paid per hour according to the service they provide. Only a minority of the patients, however, are administrative employees who receive these types of benefits. The average daily wage of an oil industry worker is 60000 rials. Therefore, the cumulative financial loss caused by absenteeism due to CHD in the oil industry adds up to more than 4800 million rials.

This figure does not include indirect costs incurred by loss of productivity due to premature death. The overall total cost was calculated at 27.57 billion rials, which is approximately $12 \%$ of the running bud- get of the NIOC Healthcare Organization for the year 1999-2000.

\section{Discussion}

In the Iranian oil industry, the economic burden of CHD is significant, since both the direct cost of diagnostic and therapeutic interventions and indirect costs due to loss of productivity, permanent disability or premature death are staggering. The oil industry situation may be representative of the situation in the country as a whole [14]. According to figures released by the Iranian Ministry of Health and Medical Education, CHD is the leading cause of death in the country [15].

In the USA, in spite of extensive population-scale prevention programmes during the past 30 years, CHD is still the leading cause of death [11]. Likewise, the leading

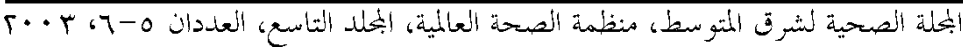


cause of early and permanent disability in the USA is CHD [11].

A recent study estimated direct and indirect costs of CHD in Germany to be DM 39000 million and DM 73000 million respectively, or a total burden of DM 112 billion [16]. In 1993 the direct cost of CHD in New Zealand was estimated at NZ\$ 200 million [17]. In Switzerland during the same year, US\$ 21 million was spent on every 100000 patients with heart disease [18]. The financial burden imposed by the loss of productivity due to CHD death in the state of California in 1991 was estimated at US\$ 5300 million [19]; the 5-10 year cumulative direct costs in 1995 dollars for all patients with CHD were estimated to be US\$ 71.5 billion and US\$ 126.6 billion respectively [20]. In the USA as a whole, the calculated overall cost of cardiovascular disease in the year 2000 was US\$ 326.6 billion (US\$ 185.8 billion direct and US\$ 140.8 billion indirect) [11].

The economic cost of coronary heart disease is so heavy that even a small reduction in incidence of CHD will produce remarkable savings. In Finland over the past 20 years widespread preventive measures have reduced cardiovascular mortality by $50 \%$, accompanied by a $40 \%$ reduction in per capita cost of treating CHD in the 3564 year-old age group [21]. This emphasizes the large-scale cost-effectiveness of preventive measures and policies and risk factor modifications [22].

In the wake of studies instituted by the USA National Institutes of Health, preventive programmes have become a fixture of health policy planning over the last 30 years. The USA government will provide the Centers for Disease Control and Prevention with US\$ 25 million to further strengthen its cardiovascular prevention programmes in 18 states where CHD prevalence is highest.
The oil industry is the Islamic Republic of Iran's main source of income. Prevention of economic damage from CHD is of paramount importance in order to preserve a productive workforce. Tragically, 65\% of those with acute CHD admitted to the NIOC Central Hospital in 1999-2000 were aged between 40 and 55 years, which are usually the most fruitful years of a person's life and career.

The diagnostic and therapeutic costs of CHD patients in our study were estimated with the heavily subsidized care and equipment offered by the NIOC Central Hospital, e.g. angioplasty balloons, stents and catheters. If we were to include in our calculations the costs of subsidies, outpatient services and indirect costs from structural and instrumental wear and tear and loss of manufacturing output and productivity due to premature coronary death and disability, we would have a figure far higher than 26770 million rials for 1999-2000.

There is little choice for the oil industry but to institute a CHD prevention plan in order to preserve a healthy workforce and to maintain output and productivity. This is a tall order, which requires collaboration between senior management within the industry and healthcare medical and paramedical staff.

\section{Acknowledgements}

The authors acknowledge the help given by the Medical Records Office and Cardiology, Coronary Care and Cardiac Surgery Units of the NIOC Central Hospital. The authors also wish to thank Ms Mandana Fatani, IT assistant, and Ms Mojgan Sharifi, for her secretarial skills. 


\section{References}

1. Janus ED et al. The modulation of Asia: Implications for coronary heart disease. Circulation, 1996, 94:2671-3.

2. Reddy KS, Yusuf S. Emerging epidemic of cardiovascular disease in developing countries. Circulation, 1988, 97:596601.

3. World Health Organization Multinational Monitoring of Trends and Determinants in Cardiovascular Disease (MONICA) Project: A worldwide monitoring system for cardiovascular disease. World health statistics annual, 1982, 27:149.

4. World Health Organization Multinational Monitoring of Trends and Determinants in Cardiovascular Disease (MONICA) Project: Myocardial infarction and coronary deaths in the World Health Organization. Circulation, 1994, 90:583-612.

5. Pearson TA, Jamison DT, TregoGutierrez Y. Cardiovascular disease. In: Jamison DT, ed. Disease control priorities in developing countries. New York, Oxford Medical Publications, 1993.

6. Tao $\mathrm{S}$ et al. Coronary heart disease and its risk factors in the People's Republic of China. International journal of epidemiology, 1989, 18(S1):S159-63.

7. People's Republic of China-United States Cardiovascular and Cardiopulmonary Epidemiology Research Group. An epidemiological study of cardiovascular and cardiopulmonary risk factors in four populations in the People's Republic of China. Baseline report from the PRC-USA collaborative study. Circulation, 1992, 85:1083-96.

8. Reddy KS. Cardiovascular disease in India. World Health Organization statistics quarterly, 1993, 46:101-7.

9. Gupta R, Gupta VR. Meta-analysis of coronary heart disease prevalence in India. Indian heart journal, 1996, 48: 241-5.
10. Gupta R, Singhal S. Coronary heart disease in India. Circulation, 1997, 96: 3785.

11. Heart and stroke statistical update. Dallas, American Heart Association, 2000.

12. Habibi HR et al. Costs of acute myocardial infarction and its consequences in Iran. Medical journal of the Islamic Republic of Iran, 1997, 11(S1):S126.

13. Mark DB. Medical economics of interventional cardiology. In: Toppi EJ ed. Textbook of interventional cardiology. Philadelphia, WB Saunders, 1999.

14. Sarrafzadegan $\mathrm{N}$ et al. Priorities in cardiovascular disease prevention in Iran. Iranian heart journal, 1998, suppl.:131.

15. Ministry of Health and Medical Education. Report of the 3rd evaluation of health-for-all strategies up to 2000. Tehran, Ministry of Health and Medical Education, 2000.

16. Klever-Deichert $G$ et al. Kosten koronarer Herzkrankheiten uber die verbleibende Lebenszeit von KHKFallen-Eine Analyse des aktuellen Bestandes an KHK-Fallen in Deutschland aus gesellschaftlicher Perspektive. [Costs of coronary heart diseases over the remaining life time in coronary heart disease cases-Analysis of the coronary heart disease cases in Germany from the social perspective.] Zeitschrift für Kardiologie, 1999, 88: 991-1000.

17. Scott WG, White HD, Scott HM. Cost of coronary heart disease in New Zealand. New Zealand medical journal, 1993, 106(962):347-9.

18. Sagmeister $\mathrm{M}$ et al. An economic analysis of ischaemic heart disease in Switzerland. European heart journal, 1997, 18(7):1102-9.

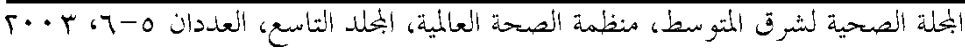


19. Fox P et al. The economic costs of cardiovascular disease mortality in California, 1991. Journal of public health policy, 1996, 17(4):442-59.

20. Russell MW et al. Direct medical costs of coronary artery disease in the United States. American journal of cardiology, 1998, 81:1110-5.
21. Kiiskinen $U$ et al. Does prevention of cardiovascular disease lead to decreased cost of illness? Twenty years experience form Finland. Preventive medicine, 1997, 26(2):220-6.

22. Store NJ. The clinical and economic significance of atherosclerosis. American journal of medicine, 1996, 101(4A):6S.

\section{WHO CVD-risk management package for low- and medium- resource settings}

The WHO CVD-Risk Management package contains a variety of components to guide healthcare providers and health systems, even those with very minimal resources, to more effective CVD risk management through easy-to-follow risk-assessment and risk-management algorithms; lifestyle counselling protocols; drug treatment protocols; referral pathways; and follow-up schedules. The package has been designed primarily for the management of cardiovascular risk in individuals detected to have hypertension through opportunistic screening. However, it could be adapted for use with diabetes or smoking as entry points. The package is meant to be implemented in a range of health-care facilities in low- and mediumresource settings, in both industrialized and developing countries. The document can be obtained from Marketing and Dissemination, World Health Organization,20 Avenue Appia, 1211 Geneva 27, Switzerland (tel: +41 22791 2476; fax: +41 22791 4857; email: bookorders@who.int). It is also available free on line at: http:// whqlibdoc. who.int/publications/2002/9241545852.pdf

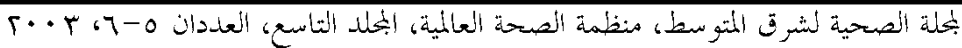

